\title{
Morphological Study of Tricuspid Valve And Its Variations in Adult Human Hearts.
}

\author{
Babita Kujur $^{1}$, Narendra Thakur ${ }^{2}$ and Renu Prasad ${ }^{3}$ \\ ${ }^{1}$ Junior Resident, Department Of Anatomy, Rajendra Institute Of Medical Sciences, Ranchi \\ ${ }^{2}$ Professor, Department Of Anatomy, Rajendra Institute Of Medical Sciences, Ranchi \\ ${ }^{3}$ Professor And H.O.D, Department Of Anatomy, Rajendra Institute Of Medical Sciences, Ranchi
}

\begin{abstract}
Introduction: The tricuspid valve is a heterogeneous structure with great variability in its structure and has remained unexamined despite intense interest in cardioanatomy. The tricuspid valve complex is of great clinical importance in the light of progress in cardiosurgery and the development of novel operating techniques.

Materials and methods: The present work was done by dissecting 42 formalin fixed adult human hearts. The sex of human was not considered. The following observations were taken (a) number of cusps (b)number of papillary muscles and their variations.

Observations and results: It was observed that the number of leaflets attached to the tricuspid valve annulus was three, namely anterior, posterior and septal leaflet in 100\% of cases and no accessory leaflet was found. On inspection of the interior of right ventricle it was found that the anterior and posterior papillary muscles were present in $100 \%$ of cases and in $2.3 \%$ of cases septal papillary muscle was absent. In one case, three accessory papillary muscles were found in the posterior wall of right ventricle and in one case, two accessory anterior papillary muscles were present. The anterior papillary muscle arose from the right anterolateral ventricular wall. It was single headed in 33 cases and double headed in 9 cases. The posterior papillary muscle arose from posterolateral ventricular wall. It was single headed in 16 cases, double headed in 26 Cases.

Conclusion: Anatomical variation in the morphology of the tricuspid valve may help cardiac surgeons during surgical procedures conducted for correction of their defects.
\end{abstract}

Keywords: Human heart, right ventricle, tricuspid valve, papillary muscle, variation

\section{Introduction}

The tricuspid valve is a heterogeneous structure with great variability in its structure and has remained unexamined despite intense interest in cardioanatomy. The number of cusps, their configuration and their size are still controversial. Although the right atrioventricular valve has three leaflets; autopsy series suggest that the number of leaflets may vary or that accessory leaflets may be found between the main leaflets, they consist of a fold of endocardium strengthened by fibrous tissue (Walls, 1995) [1]. One of the first who paid attention to the presence of accessory cusps was Tandler in 1913[2].Accessory cusps were also described by Testut and Latarjet in 1923[3], Jastrzebski in 1926[4], Wafae et al in 1990[5], Gerola et al in 2001[6] and Skwarek in 2007[7]. According to Silver et al (1971) - The tricuspid valve annulus is best seen from its atrial aspect. It is roughly triangular and its margins are described as antero-superior, inferior and septal corresponding to the lines of attachment of the valvular leaflets[8]. The atrio-ventricular valve develops from the excavation of the supporting ventricular myocardium (Steding and Seidl, 1993)[10]. The edges and ventricular surfaces of the cusps receives the attachment of chordae tendineae, collagenous cords, which diverge from the papillary muscles and prevent the cusps from being everted, when the ventricle contracts. [8] The ventricular surface of the cusps are divided into three zones - rough zone, clear zone and basal zone.[8,9] There are three papillary muscles in the right ventricle - anterior, posterior and septal papillary muscles (Moore, 1992)[11].The dynamic progress in therapeutic and diagnostic cardio invasive procedure implies a marked rise in interest in studies of cardiac anatomy and it is reasonable therefore to resume research on the tricuspid valve.

\section{Materials and methods}

The present work was carried out in department of Anatomy, Rajendra Institute of Medical Sciences (RIMS), Ranchi, Jharkhand. This work was done by dissecting 42 formalin fixed adult human hearts. The sex of human was not considered.

Collection of specimens: The adult human hearts were obtained by dissecting formalin fixed cadavers allotted to the undergraduate medical students of department of anatomy, RIMS, Ranchi, Jharkhand. Few human hearts, used earlier by a senior post graduate student of RIMS, for his dissertation work on coronary arteries 
were also utilized for the present study. Some of the hearts were also collected from the Department of forensic medicine and toxicology, RIMS, Ranchi.

Method of dissection of already removed hearts : Dissection was performed according to the standard techniques.

Exposure of tricuspid valve: To expose the tricuspid valve, incision was begun at the inferior vena cava with scissors and cut into the right atrium staying about 0.5 to $1 \mathrm{~cm}$ above the tricuspid valve annulus. Blood clots if present were washed out from the atrial chamber. The tricuspid valve leaflets were studied and presence or absence of any accessory leaflet was noted.

Exposure of papillary muscles and chordae tendineae : The incision given earlier for exposure of tricuspid valve was extended further downward vertically along the right border of the right ventricle just above the apex of the heart. Blood clots if present were washed out from the chamber. This exposes the papillary muscles and chordae tendineae of the right ventricle. The papillary muscles of the right ventricle were identified and their shape and number were noted and tabulated. The presence of any accessory papillary muscle was also noted.

\section{Observations And Results}

Study of leaflets attached to the tricuspid valve: It was observed that the right atrioventricular valve has three, roughly triangular shaped cusps that project into the right ventricle: the anterior, posterior and septal shown in photograph no. 1. Three leaflets were present in all the specimens and no accessory leaflet was found in any of the specimen.

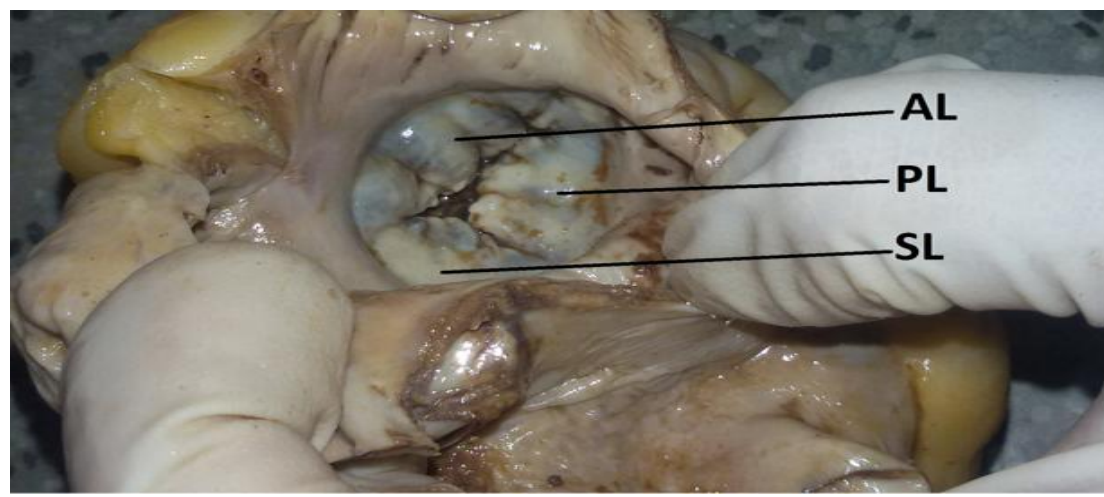

Photograph No. - 1 showing the leaflets of the tricuspid valve. AL - Anterior leaflet, PL - Posterior leaflet, SL - Septal leaflet

It was noted that the anterior cusp was the largest cusp, interposed between the atrioventricular orifice and the conus arteriosus. The posterior cusp was connected to the right margin of the ventricle and the septal cusp is attached to the ventricular septum. The bases of the cusp were attached to the fibrous ring at the atrioventricular orifice, where they are continuous with one another. The margin of each cusp was irregularly notched and thinner than the central portion. The ventricular surface of the cusps was divided into three zones 1) rough zone (distal most part) 2) basal zone (extended from the annulus to the clear zone) 3) clear zone (thin and translucent proximal portion which lies between the rough and basal zone) shown in photograph no.2.Rough zone of the cusp provided attachment to most of the chordae tendineae and the clear zone was smooth and provided attachment to few chordae tendineae.

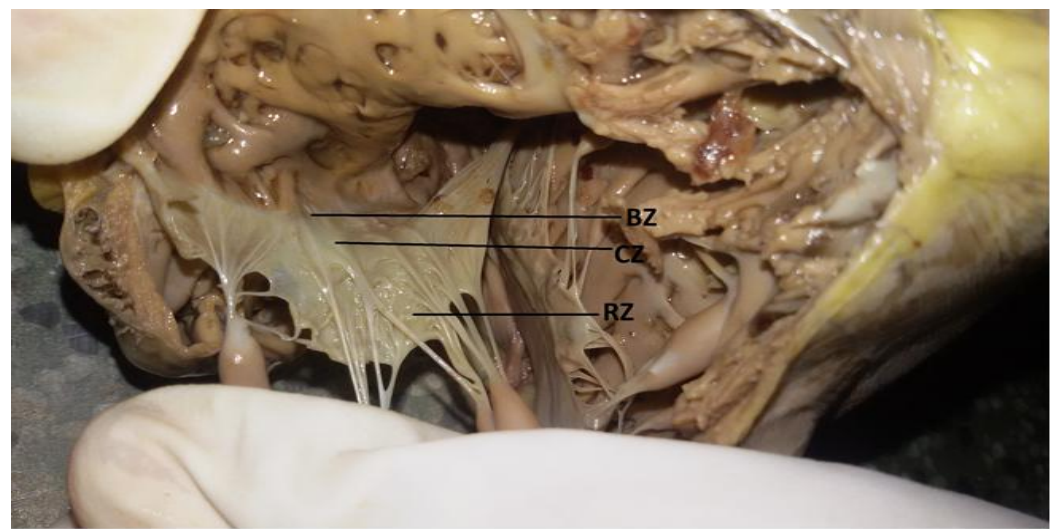

Photograph no. 2: Showing ventricular surface of a leaflet having three zones. BZ - Basal zone 


\section{CL - Clear zone, RZ - Rough zone}

Study of papillary muscles present in right ventricle : Inspection of interior of right ventricle revealed conical muscular projections in the ventricular wall which are known as papillary muscles. It was noted that the anterior and posterior papillary muscles were found in $100 \%$ of cases (photograph no.3) and in 1case (specimen no.38) septal papillary muscle was absent (photograph no.4).In one case (specimen no.29) three accessory papillary muscles were found in the posterior wall of right ventricle (photograph no.6).In one case (specimen no.41) two accessory anterior papillary muscles were present (photograph no.5).

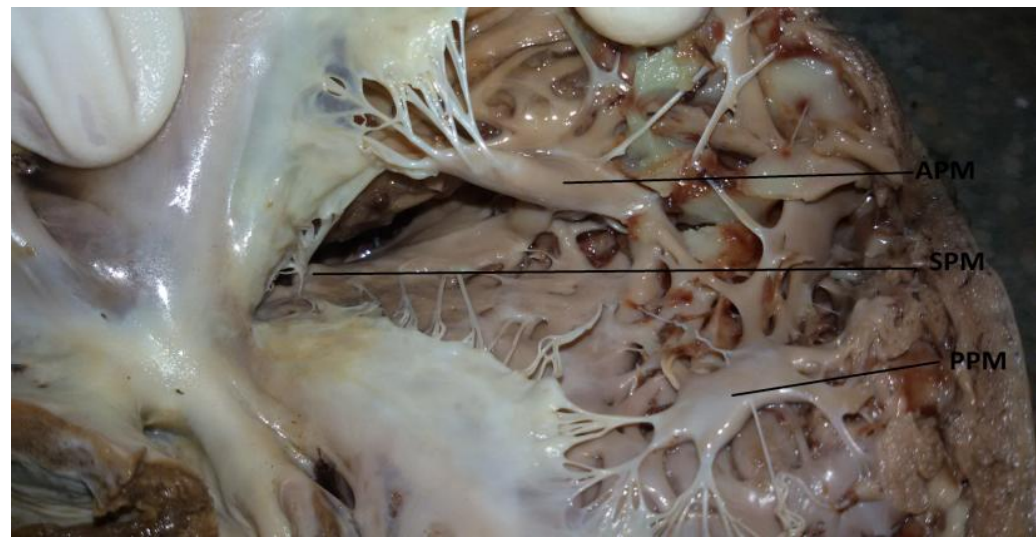

Photograph no.3

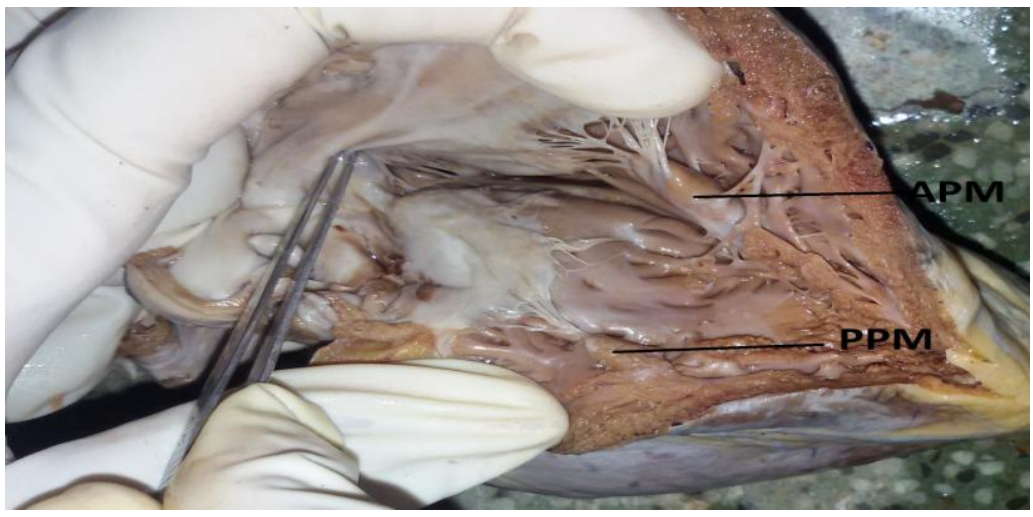

Photograph no.4

Photograph no.3 - Showing the three papillary muscles of the right ventricle. APM - Anterior papillary muscle, PPM - Posterior papillary muscle, SPM - Septal papillary muscle. Photograph no. -4- Showing right ventricle with absent septal papillary muscle.

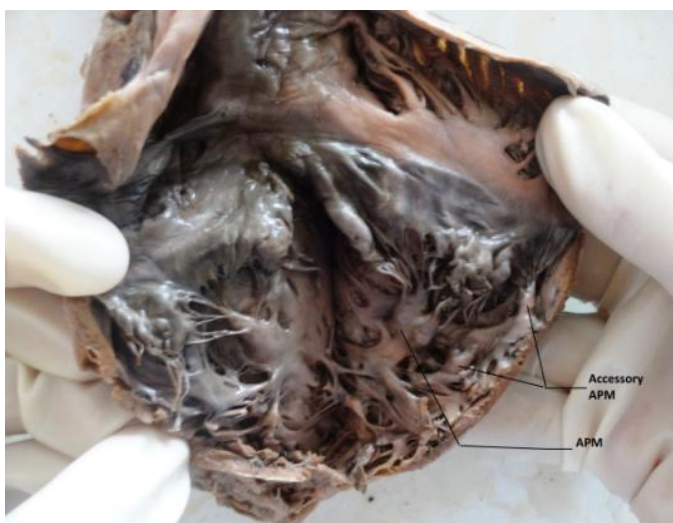

Photograph No.5

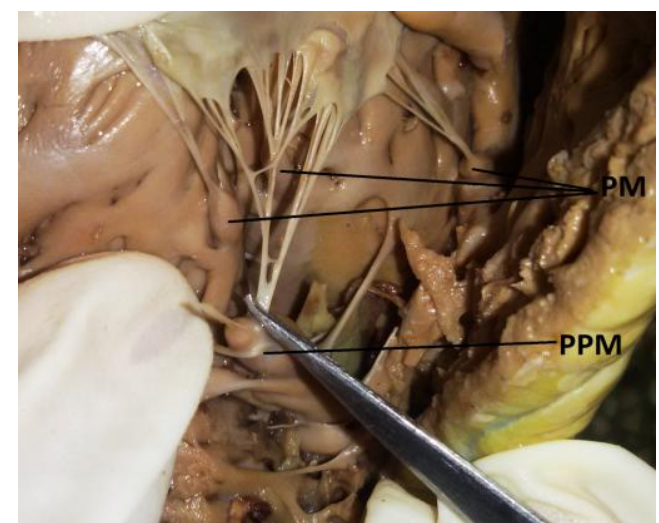

Photograph No.6

Photograph No.5: Showing accessory anterior papillary muscle. Photograph No.-6 Showing accessory posterior papillary muscle. APM - Anterior papillary muscle, PPM - Posterior papillary muscle, PM - Accessory papillary muscles. 

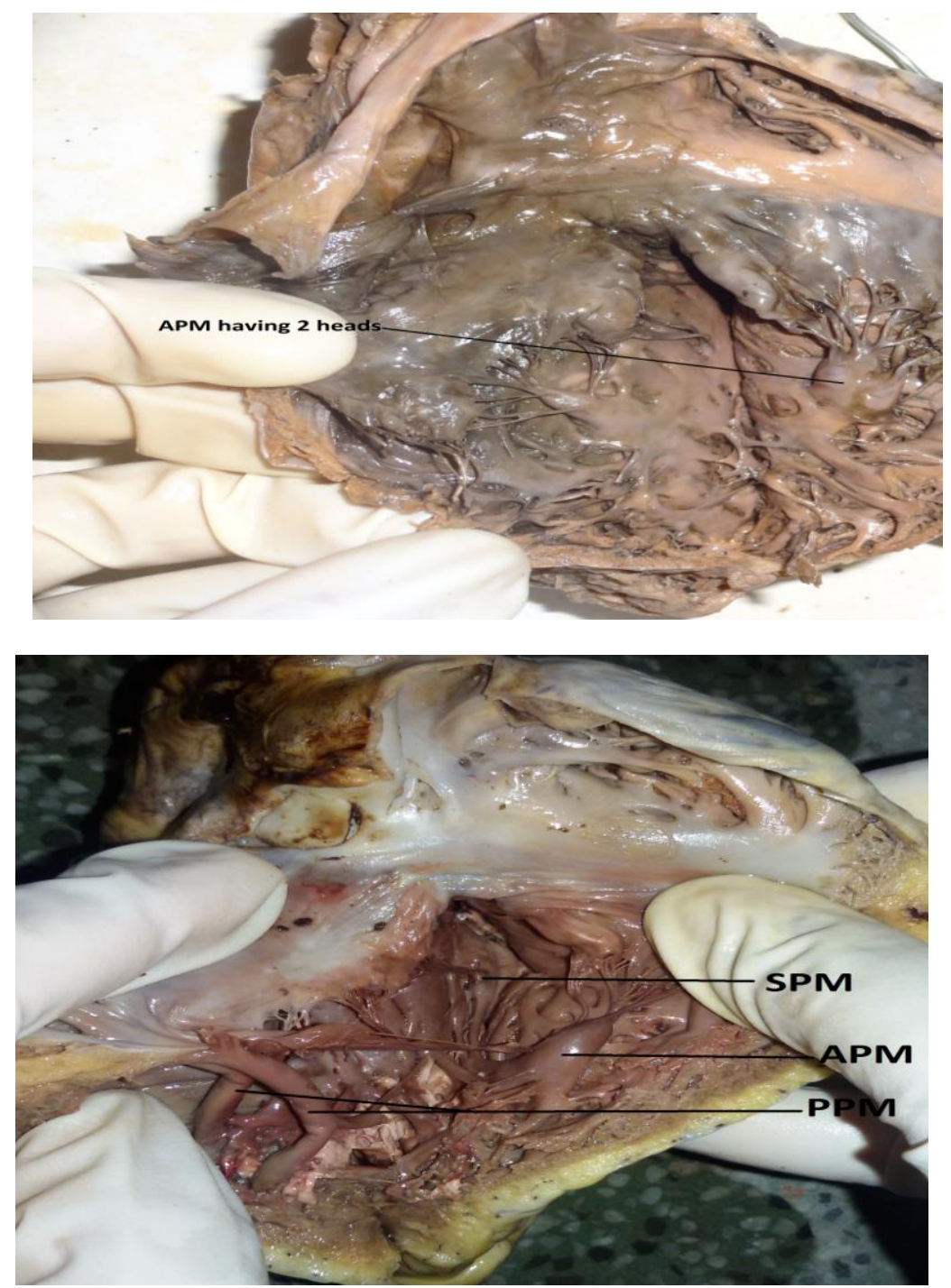

Photograph No.-7 Photograph No.-8

Photograph no. 7- Showing anterior papillary muscle having two heads. Photograph no.8 - Showing two bellies of the posterior papillary muscle. SPM - Septal papillary muscle, APM- Anterior papillary muscle, PPM -Posterior papillary muscle.

The anterior papillary muscle was noted to be the largest of the three papillary muscles of the right ventricle. The anterior papillary muscle arose from the right anterolateral ventricular wall. It was single headed in 33 cases and double headed in 9cases (photograph no.7). The posterior papillary muscle arose from posterolateral ventricular wall. It was single headed in 16 cases, double headed in 26 Cases (photograph no.8).The septal muscle was small and arose from septal wall (photograph no.3). The septal papillary muscle was absent in one case (specimen no.38) (photograph no.4)

\section{Discussion}

Leaflets: In the present study, the tricuspid valve had three cusps in all cases. No accessory cusps or commissural cusps were found. Wafae $\mathrm{N}$ et al in 1990 carried out an anatomical study in 50 human hearts of both males and females and found that, in $65 \%$ of cases commissural cusps were found independent of the number of tricuspid cusps and that the tricuspid valve was not consistently tricuspid, but was observed to present, 2, 4, 5 or 6 cusps in 72\% of cases [5]. Sutton JP et al in1995 studied 50 hearts to analyze carefully the structure of the right AV valve and to define its component parts. They did cross sectional echocardiography to study the heart valve in closed position. They reported that in $62 \%$ cases had 3 readily identifiable leaflets,30\% had 2 leaflets while in, $8 \%$ there were 4 leaflets. They were also of the view that extra scallops in the structure of the right AV valve merely allow better coaptation of the leaflet [12]. Aytac Kocak et al in 2004 studied the structure of the human tricuspid valve leaflets and its chordae tendineae in unexpected death. It was a forensic 
autopsy study of 400 cases. In 40 hearts, they found 2 leaflets (20\%), in 140 (70\%) 3 leaflets and in 20 hearts there were 4 leaflets $(10 \%)$ in deaths of non cardiac origin. They found 2 leaflets in 36 hearts (18\%), 3 leaflets in 130 hearts $(65 \%)$ and there were 4 leaflets in 34 hearts (17\%) in deaths of cardiac origin [13]. Skwarek M. et al in 2007, worked on the morphology and distribution of the tendinous chords and their relation to the papillary muscles in the tricuspid valve of the human hearts. They found 4 cuspidal forms of leaflets in $36.15 \%$ of cases [7]. In 2014, Krunal R. Chauhan, Alka Udainia et al studied the incidence of an abnormal tricuspid valve in the human cadaveric heart. They found the incidence of 4 cuspidal tricuspid valve is $10 \%$ and bicuspidal valve is $1 \%$ and the incidence of normal tricuspid valve is $89 \%$ [14].

Table no.1: Showing comparison of percentage of cases having different number of cusps with other studies.

\begin{tabular}{|l|l|l|l|l|}
\hline \multirow{2}{*}{ S.N } & Studies & \multicolumn{3}{l|}{$\%$ of cases having following no. of cusps } \\
\cline { 3 - 5 } & & 3 cusps & 4 cusps & 2 cusps \\
\hline 1. & Sutton JP et al (1995) & 62 & 8 & 30 \\
\hline 2. & Aytac Kocak et al (2004) & 70 & 10 & 20 \\
\hline 3. & Skwarek M. et al (2007) & 63.85 & 36.15 & 0 \\
\hline 4. & Krunal R.(2014) & 89 & 10 & 1 \\
\hline 5. & Present Study & 100 & 0 & 0 \\
\hline
\end{tabular}

Papillary Muscles : In present study, the anterior and posterior papillary muscles were found in $100 \%$ of cases and in one case (2.3\%) septal papillary muscle was absent. In one case, three accessory papillary muscles were found in the posterior wall of right ventricle. In one case $(2.3 \%)$, two accessory anterior papillary muscles were present in the anterior wall of right ventricle. The anterior papillary muscle was noted to be the largest of the three papillary muscles of the right ventricle. The anterior papillary muscle arose from the right anterolateral ventricular wall. It was single headed in 33 cases and double headed in 9cases .The posterior papillary muscle arose from posterolateral ventricular wall. It was single headed in 16 cases, double headed in 26 Cases. Nigri GR et al in 2001[15] studied the morphological characteristics of the papillary muscles and tendinous cords of the right ventricle in 79 normal human hearts. They observed the number, incidence, length and shape of the anterior, septal, and posterior papillary muscles and they counted the tendinous cords attached to each papillary muscle at their origin. They also measured the papillary muscles and the tendinous cords in situ and after removal of the right AV valve (tricuspid valve). Their findings are as follows;

A. (i) Presence of Anterior papillary muscles-100\%.

(ii). Presence of Septal papillary muscles-75\%.

(iii). Presence of Posterior papillary muscles $-100 \%$.

B. Number of heads of papillary muscles

Anterior papillary muscle: 1 head $-63.2 \% ; 2$ heads $-16.5 \%$; 3 heads $-12.7 \%$; 4 heads $-7.6 \%$.

Posterior papillary muscle: 1 head $-25.4 \%$; 2 heads $-46.8 \% ; 3$ heads-

$21.5 \% ; 4$ heads- $6.3 \%$.

In 2004, Aktas EO et al [16] studied on variations in the papillary muscles of normal tricuspid valve and their clinical relevance in medico legal autopsies. They found that the papillary muscles were conical projections of the ventricular muscle the apices which afforded attachment to the chordae tendineae. Although the papillary muscles presented great variability in number, with a minimum of 2 and a maximum of 9 , in the right ventricle there were usually 3 papillary muscles, anterior (APM) posterior (PPM) and SPM that corresponded nominally to the leaflets of the tricuspid valve. They found single APM in 80.5\% of the cases (161 cases) and a double APM in 19.5\% (39 cases). In 2005, Skwarek M. et al [17] worked on the morphology of papillary muscles of the right ventricle and they subdivided the papillary muscles of the right ventricle into 16 subtypes. In 2014, Mamatha Hosapatna et al [18] found that the number of heart specimens having double APM in right and left ventricles was 3 and 2specimens, double PPM in right and left ventricles were in 8 and 6 specimen respectively. The double headed APM was observed in 4 and 6 specimens on the right and left side respectively. The double headed PPM was observed in 4 and 9 specimens on the right and left side respectively.

Table no.2: Showing comparison of percentage of cases having single, double and multiple number of anterior and posterior papillary muscles in the right ventricle with other studies

\begin{tabular}{|l|l|l|l|l|}
\hline Sl. & \multirow{2}{*}{ Studies } & \% of cases having following no. of PM \\
\cline { 3 - 4 } No. & & APM & PPM & SPM \\
\hline
\end{tabular}




\begin{tabular}{|c|c|c|c|c|c|c|c|c|c|}
\hline & & 鄫 & 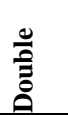 & 兽 & 追 & $\frac{0}{0}$ & 产 & $\overrightarrow{\underline{z}}$ & 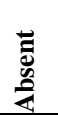 \\
\hline 1. & $\begin{array}{l}\text { Nigri GR et al } \\
(2001)\end{array}$ & $\begin{array}{l}10 \\
0\end{array}$ & 0 & 0 & 100 & 0 & 0 & 75 & 25 \\
\hline 2. & $\begin{array}{l}\text { Aktas EO et } \\
\operatorname{al}(2004)\end{array}$ & $\begin{array}{l}80 \\
.5\end{array}$ & 19.5 & 0 & 100 & 0 & 0 & 100 & 0 \\
\hline 3. & $\begin{array}{l}\text { Mamatha } \\
\text { Hosapatna } \\
\text { al(2014) }\end{array}$ & 80 & 20 & 0 & 46.66 & 53.3 & 0 & 100 & 0 \\
\hline 4. & Present study & $\begin{array}{l}97 \\
.6\end{array}$ & 0 & $\begin{array}{l}2.3 \\
8\end{array}$ & 97.61 & 0 & 2.38 & 97.6 & 2.38 \\
\hline
\end{tabular}

Table no.3: Showing comparison of percentage of cases having single, double and multiple heads of anterior and posterior papillary muscles with other studies.

\begin{tabular}{|c|c|c|c|c|c|c|c|}
\hline \multirow[t]{3}{*}{ S.N } & \multirow[t]{3}{*}{ Studies } & \multicolumn{6}{|c|}{$\%$ of cases showing following no. of heads } \\
\hline & & \multicolumn{3}{|c|}{ APM } & \multicolumn{3}{|l|}{ PPM } \\
\hline & & $\begin{array}{l}\frac{0}{000} \\
\stackrel{0}{\infty}\end{array}$ & $\frac{0}{\frac{0}{2}}$ & $\frac{\stackrel{0}{\mathscr{Z}}}{\stackrel{\Xi}{\Xi}}$ & $\begin{array}{l}\frac{0}{00} \\
\stackrel{\Xi}{n}\end{array}$ & $\frac{\frac{0}{0}}{0}$ & $\frac{\frac{0}{2}}{\underbrace{\Xi}}$ \\
\hline 1. & $\begin{array}{l}\text { Nigri GR et al ( } \\
\text { 2001) }\end{array}$ & 63.2 & 16.5 & 20.3 & 25.4 & 46.8 & 27.8 \\
\hline 2. & $\begin{array}{l}\text { Mamatha } \\
\text { Hosapatna et } \\
\text { al }(2014)\end{array}$ & 73.3 & 26.6 & 0 & 73.3 & 26.6 & 0 \\
\hline 3. & Present study & 78.5 & 21.4 & 0 & 38.09 & 61.9 & 0 \\
\hline
\end{tabular}

\section{Conclusion}

The present study gives an insight into the variations in morphology of tricuspid valve and may be used as database. The anatomy of tricuspid valve complex is highly sophisticated, but accurate knowledge of its morphology and variations is extremely important not only to understand the normal function of valves but also to improve our understanding of the pathophysiological mechanism underlying the various tricuspid valve diseases and potentially suggest ways to improve surgical treatment related to it.

\section{References}

[1]. Walls E.W. (1995).The blood vascular and lymphatic systems. In: Romanes G.J.: Cunningham'sTextbook of Anatomy. Oxford University Press, New York.Pp. 871-1008.

[2]. Tandler J (1913) Anatomie des Herzens. In: Handbuch der Anatomie des Menchen. Van Bardeleben K (ed.). G. Fischer, Jena 84-90

[3]. Testut L, Latarjet A (1948) Traite d' anatomie humaine. Vol. II. G. Doin Cie, Paris.

[4]. Jastrzebski C (1926) O zmiennosci ksztattu zastawki trojdzielnej serca I o otworach wrodzonych w jej platkach. Kosmos, Seria A, Biologia, 51:191.

[5]. Wafae N, Hayashi H, Gerola LR, Vieira MC. Anatomical study of the human tricuspid valve. Surg Radical Anat 1990; 12(1): 37-41

[6]. Gerola LR, Wafae N, Vieira MC; Jerliano Y, Smith R, Prates JC; Department of Morphology. Federal University of Sao Paulo Brasil Anatomic study of the tricuspid valve in children, Surg Radial Anat 2001 Jun; 22(3):149-153.

[7]. Skwarek M, Hreczecha J, Dudziak M, Jerzemowski J, Grzybiak M. The morphology and distribution of the tendinous chords and their relation to the papillary muscles in the tricuspid valve of the human hearts. Folia Morphol 2007; 66: 314-322.

[8]. Silver MD, Lam JHC, Ranganathan N, Wigle ED. Morphology of the human tricuspid valve. Circulation. 1971;43: 333-348

[9]. Susan Standing, Gray's Anatomy, The Anatomical Basis of Medicine and surgery 39th Edition, 2005; Elsivier Churchill Livingstone, P 1003-1004

[10]. Steding G., Seidl W. (1993) Cardio-vaskuläres System. In: Hinrichsen K.V.: Human embryologie. Springer-Verlag, Berlin, Heidelberg. Pp. 205-294.

[11]. Moore K.L. (1992) clinically oriented anatomy. 4thEdition,(1992) Lippincott William \& Wilkins, Baltimore, chapter 1, pg 111 to 127.

[12]. Sutton JP, 3rd, Ho SY, Vogel M, Anderson RH, Is the morphologically right atrioventricular valve tricuspid; J Heart Valve Dis. 1995 Nov; 4 (6): 571-575.

[13]. Aytac Kocak, Figen Govsa, Ekin O Aktas, Bahar Boydak, Ismail C Yavuz. Structure of the human tricuspid valve leaflets and its chordae tendineae in unexpected death. A forensic autopsy study of 400 cases. Saudi medical journal 09/2004; 25(8):1051-9.

[14]. Krunal R.Chauhan, Alka Udainia, C D Mehta, Kinnari Chavda ; study of incidence of an abnormal tricuspid valve in the human cadaveric heart; National journal of medical research; volume 4 ; issue 3 ; july -sept 2014;

[15]. Nigri GR, Di Dio LJ, Baptista CA Papillary muscles and tendinous cords of the right ventricle of the human heart: Morphological characteristics; Surg Radiol Anat. 2001; 23(1): 45-49.

[16]. Aktas EO, Govsa F, kocak A, Boydak B, Yavuz K; Variations in papillary muscles of normal tricuspid valve and their clinical relevance in medicolegal autopsies, Saudi Med J 2004 Sep; 25(9): 1176-1185. 
[17]. Skwarek M, Grzybiak M, Kosiński A, Hreczecha J Notes on the morphology of the accessory leaflets of the tricuspid valve in a four cuspidal model. Folia Morphol 2007; valve in the adult human heart. Folia Morphol 2004; 63: 319-324.

[18]. Mamatha Hosapatna, Anne D Souza, Aswin Das M, Supriya, Vrinda Hari Ankolekar, Antony Sylvan D Souza. Morphology of Papillary Muscles in Human Adults: A Cadaveric Study, Ibnosina J Med BS 2014;6(4):168-172. 